\title{
URBAN TRANSFORMATIONS TO PURSUE SUSTAINABILITY THROUGH RESOURCE EFFICIENCY, QUALITY OF LIFE AND RESILIENCE: A CONCEPTUAL APPROACH
}

\author{
Sigrun KABISCH${ }^{1}$
}

DOI: 10.21163/GT_2019.141.23

\begin{abstract}
:
We consider urban transformations as fundamental changes of human life and actions towards sustainability. They are an up-to-date challenge worldwide as more than $50 \%$ of the population is living in cities and the share and total amount of urban dwellers is further growing. The UN's sustainable development goals (2015) as well as the "New urban agenda" which was the final declaration of the Habitat III-conference in 2016 provide both a general normative agenda and a commitment of the UN member states to secure resilient livelihoods for all people. To reach resource efficiency, quality of life and resilience as core dimensions of the conceptual approach, appropriate strategies are necessary which deal with the management of scarce resources such as restricted land, drinking water or energy. Furthermore extreme weather events which cause flooding, storms or heat stress impacting living conditions in cities need increased consideration. These challenges require an interdisciplinary research agenda which include the human factor and its behavioral change, awareness raising, knowledge and the willingness to participate.
\end{abstract}

Key-words: Environmental Resources, Resilience, Sustainability Goals, Stakeholder Participation, Urban Transformations, Quality of Life.

\section{WHY URBAN TRANSFORMATIONS}

Urban transformations are fundamental changes of human life and actions towards sustainability. They are an up-to-date challenge worldwide as more than $50 \%$ of the population is living in cities and the share and total amount of urban dwellers is growing dramatically (United Nation, 2015a). Furthermore, cities consume more than $60 \%$ of energy, they produce about $75 \%$ of the global carbon emissions and use more than $60 \%$ of the residential water (European Environment Agency, 2009, Grimm et al., 2008). This resource consumption is accompanied by a growing urban land change.

Seto, Fragkias, Gunneralp and Reilly (2011) assume an increase of urban land by $1.5 \times$ $10^{6} \mathrm{~km}^{2}$ by 2030 . This process diminishes the agricultural land which was used for food production adjacent to the cities, impacts the local climate and threatens the biodiversity and the related ecosystem services (Elmquist et al., 2013). Additionally, extension of urban land use causes enlarged technical and social infrastructure provision and growing transport. All in all, there is an increased use of scarce natural resources in urban areas.

The major question revolves around the fair distribution of resources within the urban context to provide and ensure urban quality of life for all citizens. This is strongly related to power relations and different interests of decision makers.

\footnotetext{
${ }^{1}$ Department of Urban and Environmental Sociology, Helmholtz Centre for Environmental Research

-UFZ, Leipzig, Germany, sigrun.kabisch@ufz.de
} 
Nevertheless, the sheer number of urban dwellers, the tempo of urbanization and its far-reaching consequences require completely changed development pathways towards sustainability to ensure peaceful living together in densely settled urban regions.

There is consensus that overall urban developments are mostly not sustainable in terms of resource use, social equity and inclusion, economic welfare and environmental justice. Accordingly, recently approved programs and declarations put the need for ambitious structural transformations to reach sustainability at the center stage of decisions. The 2015 United Nations Sustainable Development Summit marked a turning point with its declaration on "Transforming our world - the 2030 agenda for sustainable development" (United Nation, 2015b). Within the 17 Sustainable Development Goals (SDGs), goal no. 11 "Make cities and human settlements inclusive, safe, resilient and sustainable" (UN, 2015b) puts emphasis on urban areas. This way, for the first time a UN declaration ascribes cities a major importance as places of human habitat.

Besides goal 11 also other goals are closely connected with urban life such as goal 1 "end poverty", goal 3 "ensure healthy lives" or goal 6 "provide clean water and sanitation" overlay and cumulate in urban areas. Even goals that at first glance seem less connected to urban life such as goal 15 "halt biodiversity loss" are concerned: Urbanization threatens global biodiversity but "Cities can reconcile [...] biodiversity by creating environments that are ecologically sustainable" (Convention on Biological Diversity, 2012). This variety of goals and the respective targets that specify each goal mark the complex and diverse character of urban structures and challenges, which require innovative, tailored and adapted approaches and pathways to reach the goals and targets.

\section{UNDERSTANDING OF URBAN TRANSFORMATIONS}

Urban transformations can be understood as fundamental, partly radical, multidimensional and in many cases non-linear alterations in and of cities. As a normative concept urban transformations are directed towards sustainability (Kabisch and Kuhlicke, 2014). This is in accordance with many other political and scientific expressions (e.g. United Nation Habitat, 2016; WBGU, 2016; Pickett et al., 2013; McCormick et al., 2013). The concept stands for processes, in which stakeholders and decision-makers develop and execute innovative solutions to go in line with the SDGs in their local context. This encompasses examples of collective and individual alterations in behavior, economic and power relations or technological innovations.

Often, transformations are described as interlinkages of economic change, technical innovations, organizational and institutional alterations as well as social and political change, directed towards sustainability (McCormick et al., 2016; Van den Bergh, Truffer and Kallis, 2011; Markard, Raven and Truffer, 2012; Forrest \& Wiek, 2014). Moreover, in practice of urban development selected sectors or themes, which have their own complexity, are in focus. Examples are infrastructure transformations (Bolton \& Foxon, 2015) or energy transformations (Moloney \& Horne, 2015).

Due to the variety of trends and their specific local impacts in cities, different transformation paths towards sustainability are necessary. This means that cities do not follow one single or clear-cut path. Rather, multiple urban transformation processes take place and can interfere at the same time in different forms, shapes and time steps. They may pursue intermediate and final goals according to the various stakeholder interests involved, as well as available resources. Accordingly, it has been acknowledged to speak of 'urban transformations' in plural (Rink et al., 2015). 
In light of these manifold challenges, urban transformations towards sustainability can only succeed if innovative scientific solutions and governance approaches are developed and implemented. Especially governance approaches have to critically consider existing institutional, political and power contexts with respect to their capacities to facilitate, enable or hinder transformations. Thereby, local key actors and city leaders push actions and programs for innovative solutions which are steps and components on the way towards urban sustainability. But the success finally depends on the engagement of charismatic leaders and a strong participation of the civil society.

Having these ambitious societal tasks in mind, their scientific operationalization requires an appropriate research strategy. Coming from a socio-environmental research background, the presented conceptual frame includes resource efficiency, quality of life and resilience as major dimensions.

\section{DIMENSIONS OF URBAN TRANSFORMATIONS}

The three dimensions resource efficiency, quality of life and resilience include a normative and an analytical connotation as well. Furthermore, these dimensions are intensively interrelated producing both, synergies and conflicts or trade-offs. Therefore, they are used in order to develop a coherent research perspective including conceptual debates and empirical evidences (Kabisch et al., 2018).

\subsection{Resource efficiency}

Concerning resource efficiency, the analysis and evaluation of urban resource use in close relation to technical infrastructure services, institutional framings and governmental reflections are addressed. In particular unprecedented land consumption, changing urban energy services, challenges of water quality and water scarcity, deficient sanitation, air pollution and biodiversity losses are in focus. The increasing competition on scarce land, affordable energy or sufficient drinking water brings about the question how to use the available resources in an "efficient" manner and avoids any kind of wasting. Generally, resource efficiency is an attempt to create or produce the same or even a better output with less input.

The higher the efficiency of a system is, the better its input-output relation (Fang et al., 2013). This notion of mere technical efficiency has to be recharged by considerations of "economic efficiency" which also takes into account the opportunity costs of technicallyefficient alternatives. Thus, economic efficiency is value-driven while technical efficiency might be misleading by using simple input-output relations. To make it even more complicated: technical and economic efficiency have to be addressed due to their effects for social equity and livability, too (Gawel \& Kuhlicke, 2018).

Similarly, the transformation of urban infrastructure systems, most of them designed under the premise of long-lasting stable demographic, political and economic conditions needs to take into account the wider societal context (Kiparsky et al., 2013). Inflexible pipedependent water supply and disposal systems are increasingly exposed to changing conditions such as climate changes or alteration of the population numbers influencing the number of users, as well as increasing requirements regarding efficiency. Hence, there is a need for adaptive and flexible facilities to be able to deal with variable and possibly unknown requirements and context conditions. These processes, however, question many established practices and routines as well as institutionalized decision and policy-making processes in terms of urban transformations. 
Further examples for the efficient use of resources are retrofitted buildings to reduce energy consumption (Vandevyvere \& Nevens, 2015) and the maintenance and enlargement of urban green spaces (Haase et al., 2014), to make cost-efficient benefit out of the delivered ecosystem services such as reduction of air pollution and decrease of the urban heat island effect.

In our understanding, the efficiency of resource use in urban areas, particularly with regards to land, energy, water, ecosystem services and biodiversity can and must be improved. It is vital to pay attention to the socio-economic and organizational-institutional context of urban development, the technological advancements and innovations, environmental impacts as well as governance processes in a broader sense. It is a transformation field which in general provides major prerequisites to improve at the same time urban quality of life and city's resilience.

\subsection{Quality of life}

Quality of life is a multidimensional concept that includes issues ranging from material living conditions to personal and social well-being as well as environmental circumstances. It includes immaterial as well as material, subjective as well as objective, individual as well as collective elements of welfare, satisfaction and happiness (Marans \& Stimson, 2011). Therefore, the availability and the access to resources is a core prerequisite of urban quality of life. While quality of life has increased in many areas of life and for many social groups, it has been decreasing e.g. with respect to lifestyle-related diseases, and also social inequalities persist (European Environment Agency, 2009). Thus living conditions of different socio-demographic groups with respect to environmental justice, health and wellbeing as well as social segregation should be included.

In this approach the focus is on quality of life from a social-environmental perspective. Here, the access to green infrastructure, a strategically planned and designed network of natural and semi-natural areas, in accord with other environmental features and managed to conserve biodiversity and to deliver ecosystem services (Benedict and McMahon, 2002), is basic to quality of life. People who live and reside in urban areas with a high share of green spaces, for example, have both lower mental distress and higher wellbeing than other people (White et al., 2013). Similarly, evidence suggests that high biodiversity positively affects human health (Keesing \& Ostfeld, 2015) — but access to biodiversity is not distributed equally in society (Strohbach et al., 2009).

Furthermore, improved green spaces, new parks and green areas as ingredients of urban renewal are used as market-driven endeavors targeting middle and higher income groups at the expense of less privileged residents. Thus, the urban green space development is connected with social impacts; it needs critical consideration concerning socially balanced and fair consequences (Haase et al., 2017). Equal access to valuable environmental goods and equal protection from pollution for everyone independent of any differentiating features of socio-economic status in terms of environmental justice (Walker, 2012) is thus vital to quality of life.

Subjective indicators of quality of life such as individual perceptions of living conditions including the environmental situation are at least equally important as more classic objective indicators like concentration values of environmental pollutants and other technical measures of environmental burdens (Marans \& Stimson, 2011). Therefore, to get differentiated insights into the quality of life of urban inhabitants, the distinct investigation of social, demographic, lifestyle and socio-economic groups concerning their expectations and perceptions is indispensable. 
Furthermore, the consideration of different temporal and spatial scales from the entire city to the neighborhood is essential. In order to provide a high quality of life to everyone, it is necessary to combine technical innovations, social innovations and ecological interests with participatory governance modes by involving citizens (Nevens et al., 2013; Flander et al., 2014).

In consequence, quality of life can only be achieved if a) access to natural resources and protection from environmental harm in and between cities are more equally distributed and b) this distribution process is designed in a democratic, transparent, integrative way, which allows fair access to information, knowledge and participation in decision-making.

\subsection{Resilience}

Resilience is often defined as a system's capacity to adapt or respond to singular, unique and most often radically surprising events and/or processes (Kuhlicke, 2013; Mykhnenko, 2016; Ohlsson et al., 2014). The IPCC in its report of 2014 formulates as follows: "Resilience: The capacity of social, economic, and environmental systems to cope with a hazardous event or trend or disturbance, responding or reorganizing in ways that maintain their essential function, identity, and structure, while also maintaining the capacity for adaptation, learning, and transformation." (IPCC, 2014).

To be resilient means to bounce back efficiently and to restore the status quo ex ante after a shock or crisis and, even more, to be able to change, learn, and adapt, and hence to alter structures and functions simultaneously. Cities are particularly exposed to such alterations, e.g. in terms of natural hazards and extreme weather events due to the high amount of people and assets located in risk prone areas, but also in terms of other disturbances such as terrorist attacks or financial crises which can affect every city with tremendous and far-reaching consequences. Making cities more resilient therefore means to strengthen a system against turbulences and construct functions and structures which are flexible and elastic in terms of less vulnerable during crisis (Revi et al., 2014).

Thus, resilience is not only a concrete and observable capacity that is in a normative sense desirable, but also has to take into account how actors make sense of their capacity to deal with rapid changes (Kuhlicke, 2013). New forms of governance towards the creation of 'preventive resilience' are needed in order to implement more resilient strategies and behavior. In the presented approach risk perception and risk assessments in human habitats, adaptation response measures and the planning perspective are in the chore of research.

\subsection{Synopsis}

The three dimensions resource efficiency, quality of life and resilience are interrelated and influence each other (Kabisch \& Kuhlicke, 2014; Krellenberg et al., 2017) (Fig. 1). To analyze and evaluate those interrelations, the particular context of a city in terms of its geographical location, its legal and institutional framework or its specific population development concerning growth or shrinkage has to be considered. Furthermore, there are conflicts and trade-offs between these dimensions which needs balancing. Accordingly, risks, feed-backs and synergies need to be addressed. City-specific economic, political, social or cultural contexts as well as different feasible options for policy formulation and practice solutions in terms of governance are necessary which reflects the richness of urban structures and urban landscapes. Thus, there is no transferable one-size-fits-all approach. Successful examples can act as orientation, but what is more important, that are learning effects from own experiences in the respective urban environment. 


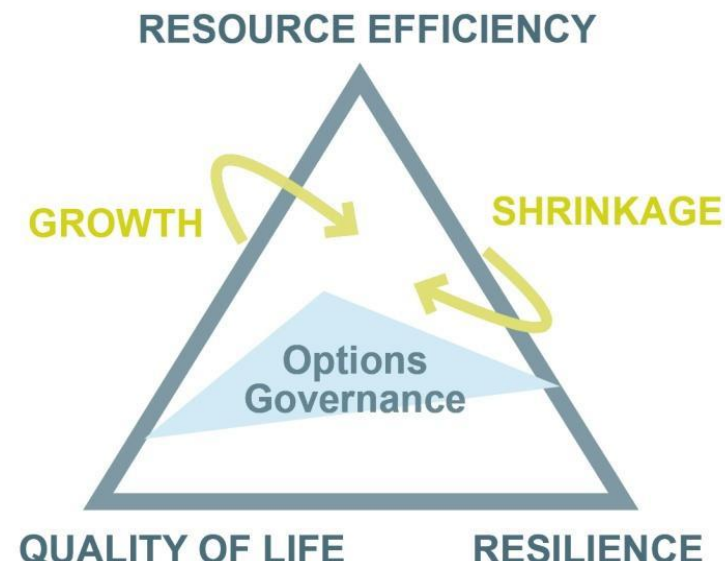

Fig. 1. Components of urban transformations: conceptual frame.

\section{FOCUSING ON LOCAL STAKEHOLDER INVOLVEMENT TO STRENGTHEN URBAN RESILIENCE}

Urban transformations occur on different geographic levels - regional, national, district related. This becomes in particular clear by drawing attention on the resilience dimension concerning disturbances and extreme events. Risks and hazards by flooding, heat stress, storms but also air pollution or noise are impacting human livelihood, wellbeing and health. In the context of weather extreme events and of climate change fundamental changes in a city are directed to adapt to, or to respond to, singular, unique and most unexpected events in terms of stress, shocks or crisis. The overall orientation is, hence, to enhance, build, or develop the capacities of actors and technical systems to cope with threatening hazardous events and, often, their occurrence at the same place (Kuhlicke, 2010; Kuhlicke, 2013; Childers et al., 2015; Carter et al., 2015). Evidence from various case studies has shown that the adaptation activities many cities are undertaking in terms of climate change are still far away from being called a transformation, although cites are, due to the concentration of people, enterprises, and infrastructure, particularly vulnerable to hazardous events. All over the world there are cities located on rivers or in low-elevation coastal zones, which make them per se more vulnerable to flooding. This means that, in the long run, many harbor cities will be increasingly threatened by the sea level rise (United Nation Habitat, 2016).

Thus, aiming at urban transformations towards a resilient city, those should be concerned with the less visible roots of urban vulnerability, such as social, cultural, economic, and political factors that often overlap and interact on different spatial and temporal scales. This is in accordance with O'Brien (2012), who argues that a broader and more holistic approach to adaptation involves viewing the vulnerability context from different spatial and temporal perspectives. Admittedly, urban vulnerability to climaterelated hazards varies in degree. And, it is, in particular, the interrelation between the spatial-structural conditions of an urban area exposed to a discrete and identifiable event in nature (or in society), together with the underlying susceptibility and response profile of its inhabitants, that shapes the degree of vulnerability (Krellenberg \& Welz, 2016). Thus, the way of tackling the challenges also very much depends on the institutional capacities. Hence, vulnerabilities are neither felt nor distributed equally between and within cities. 
In this context, the adaptive capacity of the city to climate change refers to a broad set of resources (skills, competences, and social relations). This includes the degree to which local authorities have integrated (or are in the process of doing so) climate change considerations into their long-term planning and development processes (Krellenberg et al., 2014), in order to be prepared and to react in an appropriate manner in case of intensified, extreme weather events (e.g., facilitating evacuation or relocation activities). Thus, stakeholder involvement in decision-making processes is essential, complementing the expert-led approaches (Begg et al., 2017, Fujiki \& Renard, 2018).

Capacity building strategies including improved risk communication and learning effects are part of the process. The co-design and the co-production of new and advanced instruments and tools support the handling of early warning systems, such as new web tools or disaster response training for individuals and institutions. The collaboration between experts and stakeholders concerning forecasting and now-casting as well as impactassessment by risk maps can enhance the preparedness of affected communities. Besides advanced technical equipment, the threats of the affected people and the consequences for their living conditions need consideration by decision makers and community leaders. A trust grounded relationship is an essential prerequisite to convince and facilitate behavior change towards own responsibility (Begg et al., 2016). This includes technical investments as far as possible but also behavior change, in particular after repeatedly experienced extreme events and strong damages in a short time period.

\section{CONCLUSION}

Summing up, there is a large agreement concerning the challenges of urban development. An urged need to change environmental resource consumption, behavior routines and governance modes to reach the sustainable development goals is largely acknowledged. The letter includes as much as participation and involvement of the local urban population. But there is no single and simple recipe. Local cultural, political and economic as well as environmental conditions shape the base for urban transformation pathways. Its three core dimensions resource efficiency, quality of life and resilience and their interdependencies provide a robust approach for research and concrete action in terms of urban transformations towards sustainability. This approach, grounded in socioenvironmental research, reflects the results and experiences within a five-year lasting interdisciplinary research agenda, including social and natural scientists as well as engineers. Reflecting these research results in relation to a number of related papers from other authors, we came across that this conceptual approach helps to focus the research strategy in an integrative manner and to discover research gaps. Furthermore, we recognize the need for intensive collaboration with urban planners, architects, designers and infrastructure managers to pursue sustainable urban development comprehensively.

\section{REFERENCES}

Begg, C., Ueberham, M., Masson, T. \& Kuhlicke, C. (2016) Interactions Between Citizen Responsibilization, Flood Experience and Household Resilience: Insights From the 2013 Flood in Germany. International Journal of Water Resources development, 33 (4), 591-608.

Begg, C., Callsen, I., Kuhlicke, C. \& Kelman, I. (2017) The Role of Local Stakeholder Participation in Flood Defence Desisions in the United Kingdom and Germany. Journal of Flood Risk Management, DOI: 10.1111/jfr3.12305. 
Benedict, M. A. \& McMahon, E. T. (2002) Green Infrastructure: Linking Landscapes and Communities, Island Press, Washington, D.C., USA.

Bolton, R. \& Foxon, T. J. (2015) Infrastructure Transformation as Socio-Technical ProcessImplications For the Governance of Energy Distribution Networks in The UK. Technological Forecasting and Social Change, 90 (B), 538-550.

Carter, J. G., Cavan, G., Connelly, A., Guy, S., Handley, J. \& Kazmierczak, A. (2015) Climate change and the city: Building capacity for urban adaptation. Progress in Planning, 95, 1-66.

Childers, D. L., Cadenasso, M. L., Grove, J. M., Marshall, V., McGrath, B. \& Pickett, S. T. (2015) An ecology for cities: A transformational nexus of design and ecology to advance climate change resilience and urban sustainability. Sustainability, 7 (4), 3774-3791.

Convention on Biological Diversity (2012) Cities and Biodiversity Outlook, CBD, Montreal.

de Flander, K., Hahne, U., Kegler, H., Lang, D., Lucas, R., Schneidewind, U., et al. (2014) Resilience and real-life laboratories as key concepts for urban transition research. GAIA - Ecological Perspectives for Science and Society, 23 (3), 284-286.

Elmquist, T., Fragkias, M., Goodness, J., Güneralp, B., Marcotullio, P. J., McDonald, R. I., Parnell, S., Schewenius, M., Sendstad, M., Seto, K. C. \& Wilkinson, C. (2013) Urbanization, Biodiversity and Ecosystem Services: Challenges and Opportunities. A Global Assessment, Springer, Heidelberg, New York, Dordrecht, London.

European Environment Agency (2011) Roadmap to a Resource Efficient Europe, COM (2011), 571.

European Environment Agency (2009) Ensuring Quality of Life in Europe's Cities and Towns, Tackling the Environmental Challenges Driven by European and Global Change, EEA, Copenhagen. Available from: https://www.eea.europa.eu/publications/quality-of-life-in-Europescities-and-towns. /.[Accessed March 2017].

Fang, C., Guan, X., Lu, S., Zhou, M. \& Deng, Y. (2013) Input-Output Efficiency of Urban Agglomeration in China: An Application of Data Envelopment Analysis (DEA). Urban Studies 50 (13), 2766-2790.

Forrest, N. \& Wiek, A. (2014) Learning from Success-Toward Evidence-Informed Sustainability Transitions in Communities. Environmental Innovation and Societal Transitions, 12, 66-88.

Fujikin K. \& Renard, F. (2018) A geographic analysis of post-disaster social impacts on a municipal scale - a case study of a potential major flood in the Paris region (France). Geographia Technica, 13, (2), 31-51.

Gawel, E. \& Kuhlicke, C. (2018) Efficiency-Equity-Trade-Off as a challenge for shaping urban transformations, In Kabisch, S., Koch, F., Gawel, E., Haase, A., Knapp, S., Krellenberg, K., et al. (Eds.), Urban Transformations, Springer, Heidelberg, 45-60.

Grimm, N., Faethl, S. H., Golubiewski, N. E., Redmann, C. L., Wu, J., Bai, X., et al. (2008) Global Change and the Ecology of Cities. Science, 319 (5864), 756-760.

Haase, D., Larondelle, N., Andersson, E., Artmann, M., Borgström, S., Breuste, J., et al. (2014) A quantitative review of urban ecosystem service assessments: concepts, models, and implementation. Ambio, 43 (4), 413-433.

Haase, D., Kabisch, S., Haase, A., Andersson, E., Banzhaf, E., Baro, F., et al (2017) Greening Cities-To be Socially Inclusive? About the Alleged Paradox of Society and Ecology in Cities. Habitat International, 64, 41-48.

IPCC (2014) Climate Change 2014: Impacts, Adaptation, and Vulnerability. Part A: Global and Sectoral Aspects, Cambridge University Press, Cambridge (UK), New York.

Kabisch, S. \& Kuhlicke, C. (2014) Urban Transformations and the Idea of Resource Efficiency, Quality of Life and Resilience. Built Environment, 40 (4), 475-485.

Kabisch, S., Koch, F., Gawel, E. Haase, A., Knapp, S., Krellenberg, K., et al. (Eds.) (2018) Urban Transformations, Springer, Heidelberg.

Keesing, F. \& Ostfeld, R. S. (2015) Is Biodiversity Good for Your Health? Science, 349 (6245), 235236. 
Kiparsky, M., Sedlak, D. L., Thompson, B. H. \& Truffer, B. (2013) The Innovation Deficit in Urban Water: The Need for an Integrated Perspective on Institutions, Organisations, and Technology. Environmental Engineering Science, 30, 395-408.

Krellenberg, K., Link, F., Welz, J., Harris, J., Barth, K. \& Irarrázaval, F. (2014) Supporting Local Adaptation: The Contribution of Socio-Environmental Fragmentation to Urban Vulnerability. Applied Geography, 55 (1), 61-70.

Krellenberg, K., Koch, F. \& Kabisch, S. (2017) Urban sustainability Transformations in Light of Resource Efficiency and Resilient City Concepts. Current Opinion in Environmental Sustainability, 22, 51-56.

Krellenberg, K. \& Welz, J. (2016) Assessing Urban Vulnerability in the Context of Flood and Heat Hazard: Pathways and Challenges for Indicator-Based Analysis. Social Indicators Research, 132 (2), 709-731.

Kuhlicke, C. (2010) The Dynamics of Vulnerability: Some Preliminary Thoughts About the Occurrence of 'Radical Surprises' and a Case Study on the 2002 Flood (Germany). Natural Hazards, 55 (3), 671-688.

Kuhlicke, C. (2013) Resilience: A Capacity and a Myth: Findings from an in-Depth Case Study in Disaster Management Research. Natural Hazards, 67 (1), 61-67.

Marans, R. W. \& Stimson, R. J. (2011) Investigating Quality of Urban Life, Springer, Dordrecht.

Markard, J., Raven, R. \& Truffer, B. (2012) Sustainability Transitions: An Emerging Field of Research and its Prospects. Research Policy, 41 (6), 955-967.

McCormick, K., Anderberg, S., Coenen, L. \& Neij, L. (2013) Advancing Sustainable Urban Transformation. Journal of Cleaner Production, 50, 1-11.

McCormick, K., Neij, L., Mont, O., Ryan, C., Rodhe, H. \& Orsato, R. (2016) Advancing Sustainable Solutions: An Interdisciplinary and Collaborative Research Agenda. Journal of Cleaner Production, 123, 1-4.

Moloney, S. \& Horne, R. (2015) Low Carbon Urban Transitioning: from Local Experimentation to Urban Transformation? Sustainability, 7 (3), 2437-2453.

Mykhnenko, V. (2016) Resilience: A right-wingers' ploy? In Springer, S., Birch, K. \& MacLeavy, J. (Eds.), The Handbook of Neoliberalism, Taylor and Francis Group, New York.

Nevens, F., Frantzeskaki, N., Gorissen, L. \& Loorbach, D. (2013) Urban Transition Labs: CoCreating Transformative Action for Sustainable Cities. Journal of Cleaner Production, 50, 111122.

O'Brien, K. L. (2012) Global Environmental Change II: from Adaptation to Deliberate Transformation. Progress in Human Geography, 36 (5), 667-676.

Ohlsson, P., Galaz, V. \& Boonstra, W. J. (2014) Sustainability Transformations: A Resilience Perspective. Ecology and Society, 19 (4), 1-13.

Pickett, S. T., Cadenasso, M. L. \& McGrath, B. (2013) Resilience in Ecology and Urban Design: Linking Theory and Practice for Sustainable Cities, Springer, Dordrecht.

Revi, A., Satterthwaite, D., Aragón-Durand, F., Corfee-Morlot, J., Kiunsi, R. B. R., Pelling, M., et al. (2014) Towards Transformative Adaptation in Cities: The IPCC's Fifth Assessment. Environment and Urbanization, 26 (1), 11-28.

Rink, D., Banzhaf, E., Kabisch, S. \& Krellenberg, K. (2015) Von der „Großen Transformation“ zu urbanen Transformationen. Zum WBGU-Hauptgutachten Welt im Wandel, [From the "Great Transformation" to urban transformations. On the WBGU flagship report World in Transition], GAIA - Ecological Perspectives for Science and Society, 24 (1), 21-25 [in German Language].

Seto, K. C., Fragkias, M., Günneralp, B. \& Reilly, M. K. (2011) A meta-analysis of global urban land expansion. PLoS ONE, 6 (8), 1-9.

Strohbach, M. W., Haase, D. \& Kabisch, N. (2009) Birds and the city: urban biodiversity, land use, and socioeconomics. Ecology and Society 14 (2), 31. 
United Nation Habitat (2016) New Urban Agenda. Quito Declaration on Sustainable Cities and Human Settlements for All. Available from: https://habitat3.org/the-new-urban-agenda. [Accessed April 2018].

United Nation (2015a) World Population Prospects: The 2015 Revision, United Nations, New York. Available from: https://esa.un.org/unpd/wpp/publications/files/key_findings_wpp_2015.pdf. I.[Accessed March 2017].

United Nation (2015b) Resolution Adopted by the General Assembly on 25 September 2015: Transforming our World: The 2030 Agenda for Sustainable Development. Available from: http://www.un.org/ga/search/view_doc.asp?symbol=A/RES/70/1\&Lang=E. /.[Accessed March 2017].

Vandevyvere, H. \& Nevens, F. (2015) Lost in Transition or Geared for the S-Curve? An Analysis of Flemish Transition Trajectories with a Focus on Energy Use and Buildings. Sustainability, 7 (3), 2415-2436.

Van den Bergh, J. C., Truffer, B. \& Kallis, G. (2011) Environmental Innovation and Societal Transitions: Introduction and Overview. Environmental Innovation and Societal Transitions, 1 (1), 1-23.

Walker, G. (2012) Environmental Justice: Concepts, Evidence and Politics, Routledge, London.

WBGU - German Advisory Council of Global Change (2016) Humanity on the Move: Unlocking the Transformative Power of Cities, WBGU, Berlin.

White, M. P., Alcock, I., Wheeler, B. W. \& Depledge, M. H. (2013) Would You be Happier Living in a Greener Urban Area? A Fixed-Effects Analysis of Panel Data. Psychological Science, 24 (6), 920-928. 